\title{
The Effect of Graphic Organizer (KWL Chart) on Young Learners' Reading Comprehension in an ESL Setting
}

\section{Parveen Nair A/L Sridharan, Nur Ehsan Mohd Said}

\begin{abstract}
KWL is a pre-reading strategy used to improve reading comprehension. This paper aims to discover the effectiveness of the Know-Want-Learn (KWL) strategy in improving year-4 pupils' reading comprehension is one of the elements assessed in the UPSR Examination in Malaysia. This study reports quasi-experimental research on the use of a KWL chart (graphic organizer) on year 4 pupils' reading comprehension in an ESL setting. Thirty pupils were chosen using purposive sampling in a primary school at Kuala Lumpur. The test was conducted with 30 ESL pupils of the same age group. A pretest of reading comprehension was then administered to evaluate the participants' comprehension skills. The Quasi-experimental research design used to carry out this study. Participants were separated into two different groups: an experimental group and a control group. The participants of the experimental group used the KWL Chart to answer comprehension questions; the control group received the conventional method of teaching to answer reading comprehension questions. At last, all the participants answered a post-test on reading comprehension. This innovative strategy can be used to develop pupils' reading comprehension not only for pupils in year-4 but also for pupils at other levels.

Keywords: Know-Want-Learn (KWL),Reading
\end{abstract} Comprehension, ESL learners, and Graphic organizer.

\section{INTRODUCTION}

Reading is one of the language skills that can transform people's lives. Reading skills enrich one's knowledge; reading also acts as a key to successful education. In the learn about the source. According to [31], "reading defined as a process of integrating information which is in written form to ones' background knowledge to create meaning by the readers." In other words, "There are certain strategies used to decode written forms to build meaning"[31]. Understanding the primary idea and comprehending what is written is the basic use of reading skills. Reference [37] defines reading as "a way how a reader combines printed data with the data which is written in a book." She also states that "reader utilizes a variety of reading techniques to assist with decoding (to interpret symbols into sounds or visual representations of speech) and understanding" [37].

Revised Manuscript Received on April 15, 2020.

* Correspondence Author

Parveen Nair*, Sekolah Kebangsaan Seri Anggerik, University Kebangsaan Malaysia, Bangi, Malaysia. Email: veenair64@gtmail.com

Nur Ehsan Mohd Said, Faculty of Education, University Kebangsaan Malaysia, Bangi, Malaysia.. Email: nurehsan@ukm.edu.my

(C) The Authors. Published by Blue Eyes Intelligence Engineering and Sciences Publication (BEIESP). This is an open access article under the CC BY-NC-ND license (http://creativecommons.org/licenses/by-nc-nd/4.0/) education context, pupils need to read any written materials related to any field of study in order to comprehend and

Reference [2] states that "reading skill is also like other language aptitudes, is a procedure where people enact their experience information so as to trade data starting with one individual then onto the next." He also says that "the readers conceive reading materials and combine their existing knowledge and skills in order to understand the meaning of written materials" [2]. Reading is slightly different from other language skills because it is considered as a passive skill. It does not require readers to produce messages such as speaking skills or writing skills.

In addition, "information on the genre of content, as far as how the text is composed, how information is signaled and how changes of the content may be checked, believed to be of significance in understanding reading." [3]. Reference [3] also agrees, "knowing how to search for the main idea in a paragraph and determinant meanings (author intent and implicit meaning of texts), as well as being able to identify how supportive ideas are noticeable would be beneficial to the students to process the information and comprehend the whole text."

In the ESL classroom, helping pupils to acquire reading skills is considered to be an important academic skill and a challenging area of teaching. It also acts as a foundation on which the process of teaching and learning a language is built.

[25] wrote, "Reading is also one of the most essential skills in acquiring a language besides acquiring listening, speaking and writing skill" [25]. Often, pupils in Malaysia find it difficult and sometimes challenging to read and understand the text in English because of their mother tongue interference, and the language system is completely different from English. Reading in their mother tongue is easier and comprehensible for them to understand because they have already mastered the vocabulary and are familiar with the sentence structure. Since reading is the fundamental skill that needs to be mastered in the language learning process, educators need to develop ways to teach reading skills and the ability to comprehend them efficiently. In order to comprehend a text, a pupil needs to have a remarkable command of the vocabulary of the target language, prior knowledge of the topic, and suitable skills and strategies to comprehend the message or information.

Apprehending the text or content is the main function of the reading process. Teachers need to give importance to teaching methods or instructions that allow pupils to comprehend the text. Learners who simply read without understanding the text could never read for pleasure or even gain knowledge. It is going to frustrate them and could create a negative notion about that particular language. 
Teachers assume that reading alone will make it possible for pupils to comprehend the text, and this assumption needs to be changed. Proper reading comprehension strategies should be acquainted for pupils with assistance them concoct new ideas, get significantly take part in understanding material, fundamentally investigate what they read, and apply their insight to viable just as intellectual issues.

Reference [16] defines that, "Reading is an active procedure since it includes communication between the reader and the reading material. While reading a book or a text, the reader needs to continue with the information that he/she gets from the content into his/her brain" [16]. He also adds that "Pupils are continually stood up to with new data or information, especially once they progress to primary and secondary school level and changing from 'learning how to read' to 'reading to learn"' [16]. As they go through this process, they need to be able to make good use of reading strategies to become efficient readers. Based on a research by [34] on the development of reading comprehension expertise, "A good reader typically utilizes earlier information to understand new information; pose inquiries about the content previously, during, and in the wake of reading; draw deductions from the content; monitor comprehension." They also added that "use fix procedures when meaning separates, figure out what is significant, and blend data to make sensory image or schemata" [34].

There are many teaching and learning strategies for developing pupils to become effective readers that can be used in daily instruction in ESL classrooms. Usually, most teaching and learning strategies have been developed to develop a particular strategy or skill. Reference [34] proposes, "KWL (Know, Want, Learned) system is one of teaching and learning strategies utilized mainly for information text" [34]. Reference [34] also states that "The KWL strategy (reach what I know, deciding what I want to find out, and remembering what I have learned) incorporates several elements of approaches."

The first two steps of KWL are the oral discussion between the pupils and the teacher. The main aim of the discussion is to tap on the pupils' background knowledge on the topic, to conduct a brainstorming session to find and categorize information on the topic. Next, the teacher assists to highlight disparity and inconsistencies in pupils' knowledge, and the pupils list the things they want to learn about the topic individually. At the end of the day, the pupils read new texts and share about what they have they learned.

\section{A. Problem Statement}

The pupils in the school did not perform well in English Paper 1, especially in the reading comprehension section. This has shown that the pupils' ability to comprehend reading texts is below average. This may be due to the weakness of teachers who rarely have a different strategy for teaching the learning session of English in the classroom. Therefore, there is a urgency for research on teaching reading comprehension to identify suitable and creative ways of instruction to assist pupils to respond effectively to reading comprehension questions. Reference [37] has found that "KWL strategy has shown significant improvement in primary school pupils' reading comprehension contrasted with the conventional strategy."

The importance of teaching pupils to read effectively is to

Retrieval Number: H0768044820//2020@BEIESP

ensure that pupils can read and apprehend the content effectively and purposefully. In order to achieve this goal, pupils should pre-determine the objective of their reading to ensure that they can receive maximised information. Remarkable vocabulary in the target language will be a plus in comprehending a text or a passage. Nevertheless, it does not just mean learning words, but other factors are contributing to comprehend the text as well.

Based on the aforementioned background, this research study identifies the effect of using the KWL strategy on the reading comprehension achievement of ESL pupils at the Kuala Lumpur primary school. This method could be a contribution to the literature for future reading comprehension studies.

\section{B. Purpose of research}

The purpose of this research is to find out whether the usage of the KWL Chart helps pupils in year- 4 to achieve better results in the reading comprehension sections of the examinations.

\section{Research questions}

The research questions guiding this research are as follows: 1. What are the effects of the KWL strategy on the pupils' reading comprehension in their examinations?

\section{LITERATURE REVIEW}

\section{A. Theories related to the study}

Schema theory is all about knowledge. It explains the representation of knowledge and how representation helps the use of knowledge in particular ways. Reference [35] claims that "As indicated by the schema theory, all information is stuffed into units, called schemata. Notwithstanding information itself, these bundles of information installed data about how this information is to be utilized" [35]. Thus, "schemata are utilized by readers to understand content; the printed work brings out the reader's encounters, just as past and potential connections"[35].

"Schema theory is a clarification of how readers use prior information to grasp and gain from the content"[35]. Reference [4] defines the term "schema" as a functioning association of past responses or encounters. "The key precept of schema theory assumes that written content doesn't convey meaning by itself. Rather, a text-only provides directions for readers as to how they should retrieve or construct meaning from their own previously acquired knowledge" [4]. "The schemata of a reader are arranged hierarchically, with the most general at the top down to the most specific at the bottom" [35].

Based on schema theory, the understanding composition is an interactional activity between the reader's background knowledge and the reading material. Good apprehension requires the ability to make connections to content and existing knowledge. As reference [2] points out, "each demonstration of understanding includes one's information on the world as well".

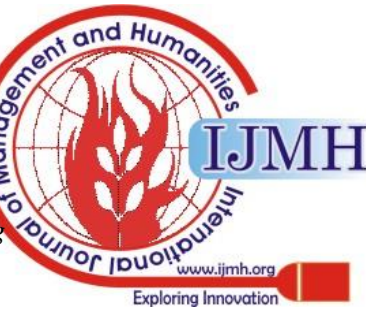


Reference [9] explains that "Reader's understanding works in two ways, from the base up to the top and starting from the top to the base of the hierarchy" [9]. They further explain, "bottom-up processing is initiated by explicit information from the content, while top-down begins with general to affirm these predictions. These two sorts of processing are occur simultaneously and intuitively, which adds to the idea of connection or apprehension between base up and top-down procedures"[9].

Reference [39] states that schema is "the earlier information increased through encounters put away in one's brain. It is a dynamic structure of information". Reference [39] also revealed that "teachers can't anticipate that their students should comprehend the chosen materials on the off chance that they don't know about the issues that an absence of schema may present on their pupils."

Reference [38] defines schema as, "Extensive portrayals of increasingly broad patterns or regularities that happen in our experience." This shows that one prior knowledge or experience will somehow be related to a new experience. Reference [2] claimed that "a reader comprehends a message when he can construe an example that gives a record of the things and events depicted in the message."

"Comprehension is the way toward enacting or developing a schema that gives a sound clarification of the items and occasions referenced in the discourse" [2]. Reference [2] agrees that "apprehension is the fundamental interaction between old and new content". They emphasized, "To state that one has grasped a content is to state that, he or she has discovered a psychological 'home' for the information in the content, or, in all likelihood that he or she has adjusted a current mental home to oblige that new information." It can be summed up that, schemata will restructure itself when there is a need for it to accommodate new information.

On the other hand, [7] gives his opinion on schema by stressing that, "a text does not by itself carry meaning. The reader brings information, knowledge, emotion, and culture that is schemata, to the printed word". Reference [7] also indicates that "reading is just unexpectedly visual. The reader contributes more information than by the print on the page". This shows one's understanding of the reading material influenced by our previous knowledge of the content.

In the ESL classroom, pupils do not have a sense of text because they do not have schemata or content knowledge about the topic they are reading. It is not enough to comprehend text language mastery, background knowledge, or information about the topic that the reader reads is also affected.

\section{A. Content Schemata}

Reference [7] defines these two as, "content schemata incorporate what we think about individuals, the world, culture, and the universe, while formal schemata comprise of our insight about discourse structure." According to this theory, the match between the text and the reader's schema determines the level of comprehension. The higher the match, the higher the comprehension. This theory stresses that comprehension is an interaction between things we acknowledged and things we are not aware of. For pupils in an ESL setting, comprehension can be boosted by contextualizing reading material related to their level, culture, and familiar things. By activating their content schemata, which is the familiarity of the text, they will be followed through the text with ease. This is supported by [15], "one of the most evident reasons why a specific content schema may neglect to exist for a reader is that the schema is socially explicit and isn't a piece of a specific reader's social foundation."

Reference [10] states that "the content must activate, in the reader, the entirety of the suitable intellectual schemata to be apprehended. When reading a story with a recognizable topic, particularly one from the local culture, L2 readers may all the more effectively enact background concepts and consequently more productively process the content". Reference [7] further added that "In addition to the fact that it is significant for the reader to have the prior knowledge to read more productively, however that information likewise should be activated." As a problem-solving step, teachers should provide pupils with the materials that pupils can relate to. Reference [9] indicates that "ESL/EFL instructors should try to limit their pupils' reading challenges by providing them with well-known content that incorporates significant cultural information.”.

\section{B. Reading Skill}

We should know what reading is. However, it is difficult to explain it briefly and correctly. Here are two examples of definitions of reading.

Reference [2] states:

"Reading is a functioning, smooth procedure that concerns the reader and the content in building meaning. Which means doesn't live on the printed page, nor is it just in the reader."

However, these two definitions appear to be abstract. This is because reading includes intricate processes and skills that vary according to tasks, purposes, and language abilities. Without knowing these elements independently, the concept of reading is still unclear.

Reading is a complex intellectual procedure of decoding symbols to build or infer meaning (reading comprehension). It is a methods for language learning, communication, and sharing information and thoughts. Like all languages, it is a complex interaction between the content and the reader that is formed by the prior knowledge experiences, mentality, and language community of the reader, which is culturally and socially arranged. The reading process requires continuous practice, development, and refinement.

Reading comprehension is the procedure of all the while removing and developing meaning through interaction and contribution with written language. This process of interaction and inclusion with content is an element of both reader and content factors that happen inside a more extensive social setting.

At the point when effective, the result of reading comprehension is a lucid mental portrayal of a text's implying that is coordinated with the reader's earlier information. 
This item is regularly alluded to as either a mental model or situation model, and is viewed as a reason for gaining from content.

The idea of this model speaks to the thoughts and the connections interfacing those thoughts that characterize what has been realized.

\section{Reading Comprehension}

"Reading comprehension is a reasoning procedure used to make importance of what an individual reads and explicitly, empowering pupils to think about and respond to what they read" [7]. "It includes process and ability like rapid word recognition, vocabulary development, text structure awareness and strategy" [7]. "Studies delineate reading as an intuitive cognitive procedure in which readers communicate with the content utilizing their earlier information and social foundation" [9]. "The achievement of reading content, the class of content structure, readers' language capability, content difficulty, and task requirements" [3].

Reference [7] states that "there are reading strategies which undertaking, methods of activity for accomplishing a specific end, arranged plans for controlling and controlling certain data." In Malaysian classroom settings, teachers need to reinforce some reading strategies to help them apprehend what they read. Pupils also need to be aware of the generic structure and function of the text to help them comprehend the composition easily.

Most of the Malaysian classrooms are packed with pupils coming from different backgrounds, each with a different level of language proficiency. Understandably, the teacher could not use a one-to-one approach to help them to comprehend the content, but the teacher needs to identify an approach that caters to most of the pupils in the classroom. Teachers need to be aware of each pupil's ability and interest their needs in assisting them in master reading comprehension.

Reading is often perceived as a complex process that requires some skill,s and readers need to use the correct strategy to understand what is written. suggested to improve reading comprehension and to develop vocabulary in language learning. Reference [29], found that, for the reading process to go well, "assurance of an understanding goal; actuation and utilization of one's own insight with respect to the content of the reading material; drawing of associations or relations between words, sentences and passages including the forecast of information and formation of portrayals is significant". "Investigation of the nature and structure of various sorts of writings; disclosure of the topic and the primary thoughts in a book alongside an outline of such; presenting and responding to of one's own inquiries is some different variables" [29]. Reference [29] also found, "arranging, controlling, checking and rectification of one's own understanding conduct; assessment of writings for their worth; and reflection on the reading exercises which have been executed and their outcomes are the significant territories of reading comprehension". Teachers can follow these guidelines in order to achieve their lesson objectives in helping pupils to comprehension relies upon variables, for example, sorts of means explicit strategies for moving toward an issue or

It is crucial for pupils to acquire the fundamental skills

comprehend the text. Learning this process can help pupils to become better and efficient readers.

\section{Factors affecting Reading Comprehension in Malaysian Classroom}

Some factors help pupils to comprehend the text that relates to each other. Reference [13] proposed two factors for understanding the text: "Within factors incorporate pupils' learning inspiration, age, inclination, and learning style. The outside factor is identified with the educator's techniques, which are utilized to make a decent classroom environment". In this case. The teacher must be responsible for identifying the problems faced by the learners in comprehending the text and must be able to create an environment or atmosphere in the classroom in order to boost the pupils' competence in reading comprehension. Teachers needed to better equip pupils with strategies that help them become successful readers. On the other hand, "the development of vocabulary and activation of prior knowledge or schema are the necessary components for all students in becoming successful readers"[2]. Reading Comprehension means "the impression of letters, fast recognition of words, identification of the capacity and significance of the various words inside a sentence and the coordination of the pieces of a sentence and successive sentences into an important entirety" [1]. The researcher finds that reading is not merely knowledge of the meaning of the vocabulary, but is of more than that. This enables pupils to grasp the content behind the written words and the ability to understand the message between the lines. It is about the reader having a good understanding or ability to apprehend a message or a piece of information from the material he or she reads. In order to do so, they must equip themselves with reading skills, including the statement of the main idea, understanding of explicit messages, the identification of communicative functions in a text, the deduction of implicit meaning from the text, and making predictions based on the text read.

Based on the researcher's observation at a specific school, the methods used by teachers to teach reading more often than not make students less interested and demotivate them from taking part in the lessons. As a result, during the teaching period, the pupils are noisy, and the material does not stimulate their interest. This could be one of the reasons why their proficiency is low. The researcher identified some of the problems faced in answering questions about reading comprehension. One of the main issues is that the pupils could not answer because they did not understand the content of the composition, and thus they could not identify the main idea of the paragraph or the text provided. For such reason, pupils do not respond to comprehension questions or, worst of all, do not take any initiative to answer the questions. This situation concludes that the pupils are taught incorrect reading techniques or that they do not know any reading strategies to help them answer questions of reading comprehension. Both the pupils and the teachers are responsible for the aforementioned problems. Several issues have been highlighted on the basis of some preliminary informal interviews with the teachers and pupils.

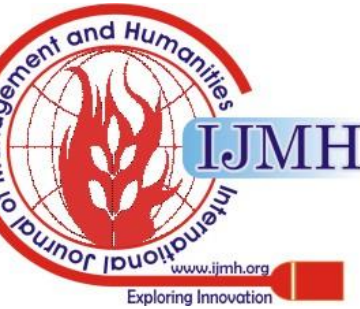


(1) The pupils were unable to comprehend the text due to weak vocabulary acquisition in the target language.

(2) Besides, the pupils were bored with the teaching method used by the teacher and had no motivation to try to answer the comprehension questions.

(3) Lack of positive reinforcement on the part of the pupils who manage to complete the task, such as small tokens, sweets, or praise, caused the pupils not even to try to do it.

Thus, they demotivated the pupils and made them make a negative-choice that would disrupt the lesson or stay passive without taking part. The conventional method of talking and reading lessons was another contributing factor to this scenario. Apart from the low level of comprehension of the text, pupils were also unaware of the techniques used to look for answers in the passage for comprehension questions, in addition to not knowing how to put the answer in a sensible way to score the marks in that section. The pupils were not aware of the Higher Order Thinking Skill strategy when attempting to answer, but they were only looking for answers in the passage alone. This is the case for all the Higher Order Thinking Skills questions (HOTS), which are incorporated in comprehension questions under examination.

\section{E. Graphic Organizer}

Reference [18] analysed Graphic Organizers as, "instruments of portrayal, outline, and displaying of information". Her research additionally inspected the utilization of graphic organizers in instructive practice to construct and systematize information. This research concluded that "graphic organizers help students in apprehending the message of the reading material by ordering and displaying ideas in the reading material" [18]. Translating a passage as read in their mother tongue or L1 is not an unusual phenomenon in Malaysian classrooms. This is a time-consuming strategy to answer the comprehension questions, especially during the examination, where they read in English, translate into L1, and process the answer before translating back into English. The other setback of this strategy apart from time-consuming is that it does not provide pupils with any ways of verifying the accuracy of their translation. To rectify this problem, graphic organizers can be used as an alternative method to comprehend the text or composition. In contrast to their accustomed practice of reading and understanding a paragraph or a text, they categorize the gist of the passage and then try to decrypt it using graphic organizers. This paper focuses on how understanding a reading passage using graphic organizers, specifically using the KWL chart as an alternative or better approach to addressing the issue of reading comprehension among year-4 pupils.

Reference [5] suggests that "educators can modify three aspects of teaching: Content, Process, and Product. By using graphic organizers, teachers modify the product." The graphic organizer is used to comprehend a text also assist in the reading process as well as the product. This method will keep them active and make a connection to schemata instead of mere translation without anything critical thinking taking place. Through the usage of contextual clues, pupils will be able to categorize and guess the content of the passage even if they do not know the vocabulary. This is supported by [23], "pupils must be urged to make associations with the content they read to expand the viability of reading". According to [14], "ability to comprehend supported by graphic organizers help a reader build up his/her understanding capacities. In this way, fusing graphic organizers in reading comprehension helps ESL learners in building up their abilities to comprehend". The text will make sense to pupils when a graphic organizer is used to depict the theme or content of a reading passage. Moreover, graphic organizers utilizing charts represent the ideas and connections between the ideas discussed in the reading materials.

Reference [9] argues that "to gain higher-request apprehending abilities, for example, evaluative and innovative, realistic coordinators give a strong establishment to understanding exacting information, outfitted with numerous strict ideas, pupils are increasingly ready to build up a more profound comprehension of reading material". "The constitution of graphic organizers is progressively appropriate for apprehension as contrasted and conventional direct note-taking of information; graphic organizers can show the relationship among ideas" [20]. Reference [29] states, Graphic Organizers: Create Links to think better. He also highlights three main ways that instructors can use graphic organizers in their class prior to teaching, while teaching, and after teaching.

"Prior to instructing, graphic organizers are utilized to comprehend the degree of the pupils as far as the content. During instruction, graphic organizers permit pupils to move toward the content cognitively in light of the fact that they help thinking. After teaching, they guide pupils as a conclusion tool or technique and encourages the pupils to comprehend their improvement."

"Graphic organizers have different structures, portrayals of items to progressive and repetitive structures. In spite of the fact that their utilization in learning exercises is favoured by individuals who have a visual style of learning, graphic organizers are helpful to various students"[18]. "Semantic map, structured overview, web, concept map, semantic organizer, story map, graphic organizer, etc." [6]. "Regardless of what the extraordinary name, a graphic organizer is a VISUAL portrayal of information. It is a method for organizing data, orchestrating significant parts of an idea or topic into a pattern using labels" [6]. Graphic organizers assist teachers as a tool to help pupils to improve their reading comprehension skills. The content knowledge of a passage becomes apparent when it is categorized into small, comprehensible units. "Graphic organizers give new language that encourages communication between instructors and learners, besides improves comprehension of the content that instructors intend to give"[28]. Graphic organizers are an effective action plan to encourage reading comprehension. Graphic organizers could be utilized efficiently while reading to check ongoing apprehension.

\section{F. KWL (Know-Want- Learn)}

The KWL method was developed by Donna M. Ogle. "The letters KWL represent three activities pupils take part as they read to learn, reviewing what they know, figuring out what they need to learn, and find out what they learn as they read" [8]. Reference [33] states that "KWL is a three-stage methodology that builds up pupils' autonomous ability in comprehending what they read.". 
The main aim of this method is to engage readers with the text deliberately and purposefully.

Reference [33] argues that "in the wake of delivering what is known, pupils create what they wish to find out about the subject giving them the self-inspiration to figure out how to learn and make up their own inquiries and it is a great method to discover a reason for comprehension."

According to [26], "KWL strategy assists kids with turning out to be good readers by getting them to do a considerable lot of the things that great readers do. This technique gets kids to read quietly with understanding”. Reference [21] believed that, "KWL could fill in as an exceptionally compelling technique in achieving the objective of all-round improvement in students' listening, speaking, reading, writing and understanding capacities."

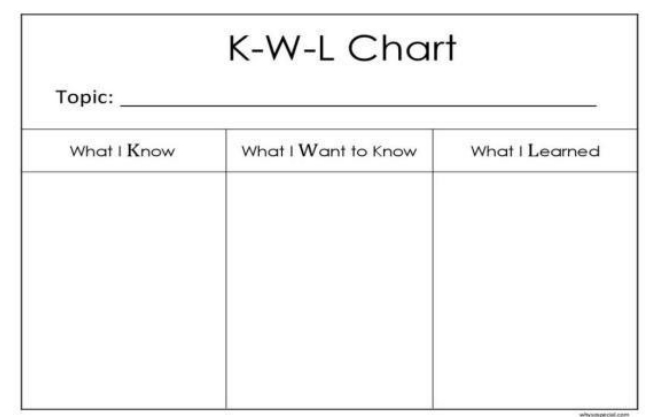

Fig 1 KWL CHART

Figure 1 shows an example of the KWL Chart. All of these three phases are an effective way to make comparisons between pupils with prior knowledge. This is a purely learner-centered method, where the teacher only facilitates learning. Reference [27] stated that " $\mathrm{K}-\mathrm{W}-\mathrm{L}$ is a procedure that models the dynamic reasoning required when reading descriptive content." Reference [33] proposed several ways to implement this method in a reading lesson,

1) Select a passage that suits the level of the learners.

2) The teacher needs to display a common chart on the board, and the pupils will also have their own chart to write down their own ideas.

3) The pupils brainstorm ideas, phrases, vocabulary based on the passage. This discussion will be written in the $\mathrm{K}$ column. This is done until pupils have run out of ideas and have an interactive discussion on what is recorded.

4) The next one is about what they want to know about the topic. The teachers and pupils record the questions in the $\mathrm{W}$ column as they discuss them. This is done until the students have run out of ideas for questions. The teacher can help pupils to change their statements to questions before writing them in the $\mathrm{W}$ column.

5) The L column will be filled in during or after the pupil has read the passage. Encourage pupils to find answers to the questions recorded in the $\mathrm{L}$ column as they read.

Teachers can have a discussion about what they have learned after completing the chart.

(7) The teacher should encourage pupils to investigate any questions in the $\mathrm{W}$ column that have not answered by the text. Reference [33] also states that "the $\mathrm{K}$ segment is to produce interest, so it assists with posting the same number of thoughts as time permits; stopping to empower the more hesitant pupils to contribute includes as many as possible."
"The objective of $\mathrm{W}$ section is to show to pupils the significance of posing inquiries of the material before reading" [33]. The last segment shows that learning happens where it causes instructors to evaluate the pupils' degrees of comprehension, yet in addition models the learning process and initiates thinking on the topic.

Ogle states, "KWL assists students with turning out to be better readers of interpretive messages and encourages educators to be more interactive in their teaching." "In the wake of doing a few KWL activities, pupils are urged to utilize it as an autonomous learning procedure to activate their background knowledge and furthermore stretch out their KWL plan to affirm the precision of their background knowledge and of what they learn" [33]. "This causes them set a positive reason for reading and record what they are learned" [17].

Afterward, [33] further improved his KWL strategy in blend with 5W questions. The strategy makes an instructional system wherein students list: "1) What is the concept; 2) What I know about; 3) What I want to know; 4) How I find out; 5) What I have learned" [33]. Right now, "works as a viable good assessment to evaluate the understanding of the content on pupils' part and assess the adequacy of the instructional process on educators' part" [33]. Teachers can apply this method to their teaching and learning so that the learners can benefit and become strategic readers. Reading will be an active process that develops its meta-cognitive.

\section{METHODOLOGY}

A quasi-experimental design was used in this study. Data were collected from two groups: a control group and an experimental group. Two variables were studied in this study. The (KWL) strategy, is the independent variable, whereas the dependent variable is pupils' achievement in reading comprehension. The experimental group was taught reading comprehension using KWL Chart, whereas the other group was taught using conventional methods.

The population of this research was the year-4 pupils in SK Seri Anggerik, Kuala Lumpur, Malaysia. The samples consisted of 30 pupils in 4 Inteleks, all of whom had almost the same level of proficiency in English. The class was divided equally, where each group consisted of 15 pupils. Group A was the experimental group; Group B was the control group. The background of the samples was almost similar, and they were not proficient ESL learners. Most of them are at the intermediate level, and a handful of them are in the proficient category. However, all of them acquired some basic reading skills that enable them to read the passages without any guidance from the researcher.

The data collected in this study is based on three instruments. The researcher used the pre-test and post-test as one of the instruments for data

collection. The data was collected by means of amultiple-choice test which comprised of twenty questions on reading comprehension. 
It was given to both the experimental and control groups in the pre-test and post-test. Samples were given only 40 minutes to complete the test. The pupils used the time efficiently to complete the test. The data collection procedure was divided into three steps accordingly.

They are pre-test, intervention, and post-test. Not only that, but the level of reading comprehension passage used must also be as objective as possible. This is to prevent any bias or favor with respect to any group. This was done using the Flesch-Kincaid Readability Test Tool to eliminate any discrepancies that may occur.

The researcher explained the research to the pupils as a first step. Both the experimental and control groups were given a pre-test to measure the competency of pupils before the treatment; the results were recorded. After the pre-test, the researcher began intervention for the experimental group using the KWL strategy, while the control group did not intervene. The post-test was administered to determine the difference in scores between the experimental group and the control group. The post-test was performed after the intervention was completed, and it was used to determine the mean differences between the experimental and control groups.

The researcher also used observation as another technique to collect data to answer the second research question, which is to measure how far the KWL strategy has motivated the readers to complete the reading comprehension task. The researcher observed both groups during treatment. It was used to see the progress of the pupils' characters when they were treated using the KWL strategy. Meanwhile, in the control group, students were only given pre-test and post-test without any treatment using KWL strategy at all.

\section{A. The Implementation of KWL Reading Strategy}

The first stage of this process is the What I Know (K) stage. This stage is made up of two sub-steps. The first sub- step is where brainstorming and discussion of the passage or topic are administered. The teacher acts as a facilitator by triggering the schemata of pupils to brainstorm what they know about the topic and write their ideas on the board. Then, the teacher distributes the three-column KWL Chart. During this phase, the teacher guides the discussion and helps pupils to try their best to come up with as many answers as possible. It is essential to keep the pupils in a position to respond to the topic. The second sub-step is simple; the pupils are required to categorize the answers they have discussed and to write them down in the "Know" column.

The second stage of this process is the What I Want to Know (W) stage. Based on the answers discussed earlier, pupils are required to create questions related to the topic that they would like to be answered. Some pupils may have differing ideas about certain information with other pupils. This will give rise to their respective reasons for rereading the article, and they can ask about that particular information. The questions are written in the second column. The third stage of this process is the What I Learned (L) stage. The teacher facilitates pupils to find out if they have found answers to written questions. As they read the passage, pupils are encouraged to write down the answers to the questions they wrote in the previous column. After reading, pupils discuss what they have learned from the passage on the topic. If the pupils have not been able to find the information they want to know, the teacher suggests further reading. Each student will be given a chance to receive answers to their questions or at least pay attention to them.

Table 1 The Implementation of Strategy

\begin{tabular}{|l|c|l|l|}
\hline Experimental & Pre-test & $\begin{array}{l}\text { Teaching using } \\
\text { group }\end{array}$ & $\begin{array}{l}\text { Post-test } \\
\text { (KWL } \\
\text { Reading) strategy }\end{array}$ \\
\hline Control Group & Pre-test & $\begin{array}{l}\text { Teaching without } \\
\text { intervention } \\
\text { (Conventional strategy) }\end{array}$ & Post-test \\
\hline
\end{tabular}

The Experimental Group

At the beginning of the session, the researcher introduced the KWL Chart to the pupils and explained how to use it effectively to understand the text as they read it. Pupils were also explained how to transfer information from the text to graphic organizers. The pupils were exposed in various ways to use the KWL Chart effectively for all the passages given to them. The teacher made them use graphic organizers on all three levels: pre-reading, reading, and post-reading.

\section{The Control Group}

The instruction materials and content used for both the experimental and control groups were the same. However, the control group did not provide any explanation on the KWL Chart and did the same during the reading process. The control group adopted traditional methods in which pupils were asked to read the text several times in order to comprehend the meaning of the given passage and answer the comprehension questions. They have been able to understand the meaning conveyed in the passage or paragraph. However, They have not been able to classify the paragraph as the main idea, the topic sentence, the supporting details, and the concluding thoughts.

Data from observation will be analyzed. Observation will be used to retrieve data on the motivation of year- 4 pupils to respond to reading comprehension using the KWL method. The data obtained from all three instruments were triangulated and discussed in the next chapter, taking into account the validity, reliability, dependability and transferability aspects.

\section{B. Data Analysis Plan}

The pre-test and post-test data were analyzed at two levels. The first level was the tabulation of the test scores, and the second level is the analysis using an appropriate formula. The data were tabulated and analyzed using the t-test formula in Equation (3.1)

$$
t=\frac{M x-M y}{\sqrt{\left(\frac{\sum x^{2}+\sum y^{2}}{N x+N y-2}\right)\left(\frac{1}{N x}+\frac{1}{N y}\right)}}
$$

Fig 2 t-test formula

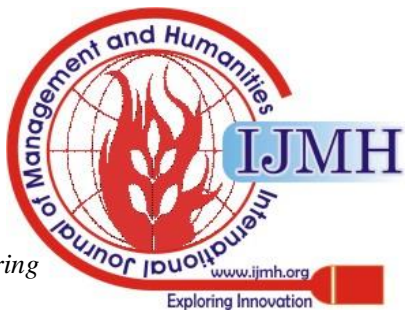


Where:

Mx : the mean score of the experimental group

My : the mean score of the controlled group

$\mathrm{Nx}$ : the number of students of the experimental group $\mathrm{Ny}$ : the number of students of the controlled group $\mathrm{x} 2$ : the total of the square deviation of the experimental group y2 : the total of square deviation of the controlled group After computing and tabulating both test scores, it is learned that there is a significant difference between the experimental and the controlled groups. The average scores were calculated from Equation (1).

mean $=\frac{\sum X}{N(1)}$

The data from the observation form will be analyzed using a thematic analysis method. The data obtained from all three instruments (pre-test, post-test, and observation forms) are discussed in the following chapter - taking into account the validity, reliability, and dependability and transferability aspects, ensuring credibility and trustworthiness.

\section{IV.FINDINGS}

\section{A. Analysis of the Pre-Test and Findings}

The pre-test in this study is seen as a tool for discovering the basic line of pupils' ability to respond to reading comprehension. The pre-test is given to all 30 pupils before the intervention stage. This test is made up of 20 multiplechoice questions based on four texts. Each text consists of five multiple-choice questions.

The multiple-choice items were created based on the UPSR format for comprehension passage, which consists of a combination of simple and difficult questions. Nevertheless, the questions raised also demanded two main criteria when designing the questions. All items must depend on the passage, and some of the items should require the reader to make an inference. There were three possible responses and two distracters for each multiple-choice question. All the distracters in multiple-choice questions were possible, and the questions would not have been answered correctly if the pupils had not read and understood the related idea in the comprehension passage related to the question. The researcher used five key areas of reading comprehension: main idea, specific information (supporting details), reference, inference, and vocabulary.

The answers were then collected for scoring on the basis of the suggested rubric. Both the experimental group and control group showed two pupils with poor performance, six pupils with low performance, five pupils with average performance, and two pupils with good performance in respective groups. Each item has a weight of two marks for the correct answers and 0 marks for the incorrect answers. The marks are then tabulated as a percentage where $100 \%$ is possible. Pupils marks were categorized based on the scale 0$20 \%=$ Low, $40-60 \%=$ Average, and $80-100 \%=$ Good.

To calculate a mean score, the formula (1) is used used. Based on calculations from Eq. (1), the mean score ( $\bar{x}$ ) of the experimental group is $33.3 \%$. On the other hand, pupils in the controlled group also had a mean score of $37.3 \%$. The standard deviation is then calculated using $(\bar{x}-x)$. The D values are then squared one by one and the total value is divided by the total number of pupils in both groups minus one using the formula, $\mathrm{S}=$. The standard deviation is 24.69

for the experimental group and 24.92 for the controlled group. The distance of scores from the mean for both groups is more

or less the same, which indicates that both groups consist of pupils who are heterogeneous and equally divided. Both groups include low-performance pupils, average performers, and good performers in answering reading comprehension.

\section{A. Analysis of the Post-Test and Findings}

The post-test was given to both the controlled and experimental groups at the intervention stage. The post-test also focused on the organization of ideas using the KWL chart. Both the experimental group and the control group were given two texts after the intervention stage and were required to answer five questions on the basis of the comprehension passage given to them. They need to choose the best possible answer from three choices given to them. The post-test scores revealed that there are ten good performers in the experimental group and six good performers in the controlled group.

The mean score of $60 \%$ is determined for the experimental group and $50.67 \%$ for the control group. The standard deviation is calculated using Equation (2). The standard deviation is 20.00 for the experimental group and

20.51 for the controlled group. The experimental group shows a higher growth from an average score of $33.3 \%$ to $60 \%$. The controlled group also shows an increase in the mean score from $37.3 \%$ to $50.67 \%$.

(2)

$$
S=\sqrt{\frac{(X-\bar{X})}{n-1}}
$$

Table 1 Pre-Test And Post-Test Mean Percentage Of Growth

\begin{tabular}{llll}
\hline GROUP OF PUPLS & PRE-TEST & POST- TEST & GROWTH(\%) \\
EXPERINENTAL GROUP & 33.3 & 60 & 80.18 \\
CONTROLLED GROUP & 37.3 & 50.67 & 35.84 \\
\hline
\end{tabular}

\section{Test of Significance}

Apart from comparing means, a t-test was also used to find the statistical significance between the two groups using The t-test formula discussed previously used to strengthen the analysis results.

The results of the t-test then checked with a critical value of t-table to see whether it is significant or not. $\square \square 5 \%$, and the number of pupils, $15+15-2=28$, found that t-table $=$ 1.70. Based on the calculation, it can be concluded that the $\mathrm{t}$ - value is lower than the critical value on the t-table. There is no significant difference in improvement between the groups; this shows that the difference in means is not significant.

\section{Thematic Analysis}

After the analysis of quantitative data, the observation form was used to analyze whether the usage of the KWL Chart helps the year-4 pupils to achieve better reading comprehension. Each time pupils use the KWL chart, pupils have been observed, and have their behavior recorded.

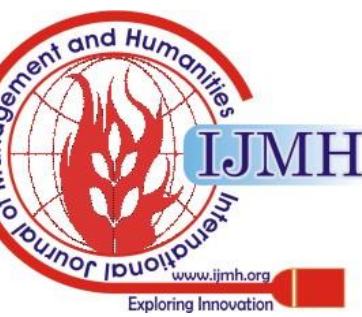




\section{Theme One: Pupils complete the task fast using the KWL chart.}

The time taken for each pupil to complete the correct answer using the KWL Chart was faster compared to the pupil who answered the comprehension questions using the convention method. For example, for passage one, pupils in the experimental group managed to outline the information fast, and it helped them to cross out the distractors easily and thus, making the answering process simpler and easier.

The pupils in the experimental group also underlined important information from the given passage in order to fill in the chart.

\section{Theme Two: Pupils engaged in answering the question} when they use KWL chart

Based on the researcher's observation, pupils who used this chart when answering reading comprehension showed more engagement in the task and did not easily give up despite encountering difficult questions. The KWL Chart makes it easier for pupils to read between the lines. The pupils were also occupied with the task and did not disturb or speak to their friends when carrying out the tasks. The KWL chart encourages pupils to search for answers to questions of reading comprehension.

\section{Theme Three: KWL chart facilitates independent} learning.

It was observed that the frequency of pupils in the experimental group raising their hands to ask questions from the teacher was lower than that of the controlled group. The teacher gave much scaffolding to pupils in the experimental group compared to the controlled group. It can be summed that when the KWL chart motivates pupils to try their own reading comprehension before looking for the assistance of the teacher. This also keeps the class under control, where the pupils ask only when they try to comprehend.

\section{DISCUSSION AND CONCLUSION}

\section{A. Discussion Of The Findings}

The findings of this study have few pedagogical implications for teaching reading comprehension in the EFL context. Teachers can apply this strategy to the teaching process reading and help learners make significant progress. The insights gained from this experiment emphasize two principles for reading instruction.

Research Question: What are the effects of the KWL strategy on the pupils' reading comprehension in their examinations?

The research question of the study was to explore the effects of the KWL strategy on the pupils' reading comprehension in their examinations. In order to find out more about this, a set of comprehension passages was used as an instrument in this study. Such questionnaires were then evaluated by means of a descriptive analysis. The findings were clearly presented in Tables 4.2 and 4.3. The results of the descriptive analysis indicated that both female and male respondents benefited greatly from the storytelling methodused to learn the English language. They claimed that the storytelling strategy in English classrooms could make them like the English language. As stated in the background of the study, these school pupils did not come from English- speaking families, so their interest in the English language was extremely low.

\section{B. Summary Of Findings}

The insight from this research stress two principles for reading instruction. To begin with, instructors should remember that prior knowledge of pupils can assist with comprehending new text. Second, the instructor's duty ought to be to build up pupils' capacity to take care of issues and to exploit whatever information or knowledge they may have. The pedagogical concept not be such a great amount on one part of learning, for example,vocabulary or translation, yet on understanding. So, students must be made aware of what is engaged with effective reading. They should enact their assets in the recreation of meaning and set up a connection between their old information and their new information. A study tool, for example, the KWL strategy might be useful. In the KWL technique, the educator is certifiably not an immediate instructor however offers help for students to learn on their own. The educators right now just assistance them to do as well as can be expected. This strategy empowers pupils to be more active and to take part in the learning process.

Educators are currently enlivened to utilize an assortment of materials in their classrooms to suit the individual wishes, interests, and abilities of their pupils. Be that as it may, this pattern doesn't prevent the significance of textbooks since the utilization of reading material successfully gives them an instrument for free learning. The KWL strategy, among others, is to be instructed and to be taught totally. The KWL strategy helps to create textbooks as important materials. It encourages students to make connections between previous data and new data, making the construction of meaning easier. Teachers should consider the limited background knowledge of the students. Considering this and other relevant factors, any teacher can engage in the effective implementation of KWL.

\section{Implications Of Research}

Reference [22] emphasizes the importance of structural discourse awareness in reading comprehension in the L1 and L2 contexts. Therefore, teachers' approach to the subject must take into account the best pedagogical skills needed to increase the students' understanding of the passage. Graphic organizers have a vital role to play in this. It helps to bridge the understanding of mere lexis to content that is more understood by students so that they can take part in a more detailed discussion of the topic. Reference [22] argued that the graphic organizers depict the discourse structure by representing the interrelationship between the ideas and patterns of the text.

The pupils' participation level in the classroom is an excellent parameter to be used. If the task is given was to be engaging and student-centered, teachers would get more active participation, and the learning process would be livelier. Graphic organizers are helping to draw students' attention to the lesson that will be taught that day. This can be especially true if the comprehension passage is too dull and brimming with facts and jargon that the students are not familiar with. Thus, by using this, the task in hand would become a student-centered activity, and an active thinking process would take place throughout the ESL classroom.

When teachers use graphic organizers to teach, they indirectly motivate pupils to create their own graphic organizers for the passages they read and comprehend;this will improve their creativity. and $\mathrm{Hu}$ 
There was a significant difference in reading comprehension between pupils who were taught by using the KWL strategy and those who were not. Since the treatments had been given, they could improve their reading comprehension.

Based on the analysis of the data collected during and after the experiment, it could be concluded that pupils could improve their reading comprehension. Most of the students in the experimental group had better reading comprehension and were enthusiastic, active, and enjoy comprehending reading texts using the KWL strategy. Their better achievement in reading comprehension can be seen on the basis that post-test scores were higher than pre-test scores.

The use of the KWL strategy had an impact on students' reading comprehension. It can be seen from the analysis of the mean score between the groups, which showed improvement even though it was not significant, where it is indicated that the KWL strategy has been effective in improving students' reading comprehension.

\section{E. Recommendations for Further Study}

Recommendations are vital for possible better research in the future. Therefore, several recommendations were suggested to improve the future of this study. Firstly, the scope of this research needs to be expanded to different types of schools, as all of them have different backgrounds of pupils. Researchers should consider applying this research to vernacular schools or schools in rural areas in order to achieve the level of disparity, if any, between urban or rural schools. By doing so, a good comparison of findings can be achieved by comparing weak students in rural and urban schools. This would help shed more light on the impact of the KWL chart on the reading comprehension of the pupils.

In addition, researchers can consider implementing the KWL chart to weak students by adapting the level of comprehension text that is more suitable for their level of resources to different levels of students, for instance, to smart students in urban schools. This will help to obtain valid and reliable data on the usefulness of the storytelling method. Another suggestion would be to lengthen the duration of the study so that ample time would be given to both the researcher and the samples to master and would imply the benefit of storytelling in teaching English. Finally, instead of involving only students in this study, the researcher can take into account the role of the teacher or the perception of storytelling as a language teaching resource.

\section{VI.CONCLUSION}

Most educators perceive teaching reading as a difficult and less interesting task. More often than not, the teacher is responsible in keeping track of pupils' progress and the need for an education system and to adjust and adapt new strategies to their level. Teachers must always must pupils to learn from the text they read and not just to answer the questions asked. Excellent educators will motivate pupils not only to read but also to help them read.

\section{REFERENCES}

1. Aarnoutse. C and Schellings. G.(2003). Learning reading strategies by triggering reading motivation, Educational Studies, 29:4, 387-409, DOI:10.1080/0305569032000159688.

2. Anderson, N. (1999). Exploring second language reading. Boston, MA: Heinle \& Heinle

3. Alderson, J.C. (2000). Assessing reading. Cambridge: Cambridge University Press.

4. Bartlett, F.C. (1932). Remembering: A study in Experimental and Social Psychology. Cambridge: Cambridge University Press.

5. Brennen, A.M .(2006). Enhancing students' motivation. Retrieved from http://www.soencouragement.org/enhancing-students motivation.htm. [14 June 2019].

6. Bromley, K., Irwin-DeVitis, \& Modlo, M. (1995). Graphic Organizers. New York: Scholastic Professional Books.

7. Brown, H.D. (2001). Teaching by principles: An interactive approach to language pedagogy. White Plains, NY: Addison Wesley Longman, Inc.

8. Carr, E. \& Ogle, D. (1987). "KWL Plus: A strategy for comprehension and summarization". Journal of Theory and Practice in Language Studies.Vol.4, No.3. pp. 3.

9. Carrell, P. L., \& Eisterhold, J. C. (1983). Schema theory and ESL reading pedagogy. TESOL Quarterly, 17, 553-573.

10. Carrell, P.L. (1987). Content and formal schemata in ESL reading. TESOL Quarterly, 21, 461- 481.

11. Carrell, P.L. (1982). Three components of background knowledge in reading comprehension. Language Learning, 33, 183-201.

12. Carrell, P.L. (1983). Some issues in studying the role of schemata or background knowledge in second language comprehension. Reading in a Foreign Language, 1, 81-92.

13. Carrell, P.L. (1987). Readability in ESL. Reading in a Foreign Language, 4, 21-41.

14. Carrell, P.L. (1988). Interactive text processing; Implications for ESL/second language reading. In P, L. Carrell, J. Devine \& D.E. Eskey (Eds.) (1988) Interactive Approaches to second language reading. Cambridge: Cambridge University Press.

15. Carrell, P.L. \& Eisterhold, J.C. (1983). Schema theory and ESL reading pedagogy. TESOL Quarterly, 17, 553-569.

16. Chall, J.S. (1983). Stages of reading development. New York, NY: McGraw-Hill.

17. Cherry, K. (2010). What is Motivation? About.com. Retrieved from http://psychology.about.com. [14 June 2019].

18. Ciascai, L. (2009). Using Graphic Organizers in Intercultural Education. Acta Didactica Nepocensia, 2(1), 9-18.

19. Darch, C., \& Carnine, D. (1986). Teaching content area material to learning disabled students. Exceptional Children, 240-246

20. Ermis, S. (2008). Using graphic organizers to facilitate elementary students' comprehension of informational text. College Reading Association Yearbook , 87-102

21. Fengjuan, Z. (2010). The integration of the know, want-learn (KWL) strategy into English language teaching for non-English majors. Chinese Journal of Applied Linguistics, 33(4), 77-83.

22. Jiang, (2012). Effects of Discourse Structure Graphic Organizer on EFL Reading Comprehension. Reading in a Foreign Language, 24(1), 84-105.

23. Kaplan, R.B. (1966). Cultural thought patterns in intercultural education. Language Learning, 16, 1-20.

24. Koh, M.Y. (1986.) The role of prior knowledge in reading comprehension. Reading in a Foreign Language, 3, 375-380.

25. Kustaryo, Sukirah. (1998). Reading Techniques for college students.

26. Lenski, S., Ehlers-Zavala, F. (2004). Reading strategies for Spanish speakers. Dubuque, IA: Kendal/Hunt.

27. Michael Susan. (2006). KWL - A Reading comprehension strategy. Available in http://www.indiana.edu. 1517/KWL.htm

28. Marzano, R. J., Pickering, D. J., \& Pollock, J. E. (2001). Classroom instruction that works: Research-based strategies for increasing student achievement. Alexandria, VA: Association for Supervision and Curriculum Development.

29. National Reading Panel (NRP). (2000). Teaching Children to Read: an Evidence-Based Assessment of the Scientific Research Literature on Reading and its Implications for Reading Instruction (Washington, DC, National Institute of Child Health and Human Development).

30. Neil Mc. J. D. (1992). Reading Comprehension: New Directions for Classroom Practice. Harper Collin Publishers. New York. p. 16. 
31. Nunan, D. (2003). Practical English language teaching. Singapore: The MCGraw Hill.

32. Nuttall, C. (1982). Teaching reading skills in a foreign language. London: Heineman Educational Books.

33. Ogle, D.M. (1986). KWL: A teaching model that develops active reading of expository text. Reading Teacher, 39, 564-570.

34. Pearson, Rochler, Dole, \& Duffy. (1992). Developing expertise in reading comprehension. New York, NY: McGraw-Hill. Inc.

35. Rummelhart, D.E. (1980). Schemata: The Building Block of Cognition. Spiro. In. R. J., Bruce, B.C. and Bsewer, B.F.(Eds). Technical Issues in Reading Comprehension, Perspective from Cognitive Psychology, Linguistics, Artificials Intelegence, and Education. Hillsdale, New Jersey : Lowrence Erlbaum Associates Publisher.

36. Ryan, R. M., \& Deci, E. L. (2000). Self-determination theory and the facilitation of intrinsic motivation, social development, and well-being. American Psychologist, 55, 68-78. http://dx.doi.org/10.1037/0003066X.55.1.68

37. Shaye, S. (2000). The effectiveness of metacognitive strategies on reading comprehension and comprehension strategies of eleventh grade students in Kuwait High School. Retrieved September 21, 2019, from http://www.lib.umi.com/dissertations/html

38. Smith, F. 1994. Understanding Reading. 5th ed. Hillsdale, NJ: Lawrence Erlbaum.

39. Xiao-hui, L., Jun, W., \& Wei-hua, W. (2007). Analysis of schema theory and its influence on reading. US China Foreign Language, 5(11),18-2 